\title{
Encoderless Flux Vector Oriented Control of Brushless Doubly-Fed Reluctance Generators
}

\author{
Milutin Jovanović \\ Faculty of Engineering and Environment \\ Northumbria University \\ Newcastle upon Tyne NE1 8ST, UK
}

\author{
Sul Ademi and Ayman Attya \\ Institute for Energy and Environment \\ University of Strathclyde \\ Glasgow G1 1RD, UK
}

\author{
Liancheng Zhu \\ School of Electrical Engineering \\ Shenyang University of Technology \\ Shenyang 110870, China
}

\begin{abstract}
An angular position and velocity observer-based sensorless flux vector-oriented control scheme for a prominent doubly-fed reluctance generator has been presented and experimentally validated. This technology allows the use of the same partially rated power converter as the traditional slipring doubly-excited induction generator, while offering competitive performance with added cost benefits of high reliability and maintenance-free operation afforded by its brushless construction. The controller viability has been demonstrated on a laboratory machine prototype for emulated variable speed and loading conditions similar to those encountered in wind turbines.
\end{abstract}

\section{NOMENCLATURE}

$\begin{array}{ll}\text { BDFRG } & \text { Brushless Doubly-Fed Reluctance Generator } \\ \text { BDF(I)G } & \text { Brushless Doubly-Fed (Induction) Generator } \\ \text { DFIG } & \text { Wound Rotor Doubly-Fed Induction Generator } \\ \text { LVRT } & \text { Low-Voltage-Ride-Through } \\ \text { MPPT } & \text { Maximum Power Point Tracking } \\ \text { WECS } & \text { Wind Energy Conversion Systems } \\ \text { DT(P)C } & \text { Direct Torque (Power) Control } \\ \text { FOC } & \text { Flux (Field) Oriented Control } \\ \text { VOC } & \text { Primary Voltage Vector Oriented Control } \\ v_{p, s} & \text { Primary, secondary winding phase voltages [V] } \\ i_{p, s} & \text { Primary, secondary winding currents [A] } \\ R_{p, s} & \text { Primary, secondary winding resistances [ } \Omega] \\ L_{p, s} & \text { Primary, secondary 3-phase inductances [H] } \\ \lambda_{p, s} & \text { Primary, secondary winding flux linkages [Wb] } \\ \lambda_{m}, L_{m} & \text { Mutual flux [Wb] and 3-phase inductance [H] } \\ \omega_{p, s} & \text { Primary, secondary winding frequencies [rad/s] } \\ p_{p}, p_{s} & \text { Primary, secondary winding pole-pairs } \\ p_{r} & \text { Number of rotor poles }\left(=p_{p}+p_{s}\right) \\ \omega_{r m}, n_{r m} & \text { Rotor angular velocity [rad/s], speed [rev/min] } \\ \omega_{s y n} & \text { Synchronous speed }=\omega_{p} / p_{r} \text { [rad/s] } \\ P_{m} & \text { Mechanical (shaft) power [W] } \\ P_{p, s} & \text { Primary, secondary mechanical power [W] } \\ T_{e} & \text { Electro-magnetic torque [Nm] } \\ P, Q & \text { Primary real [W] and reactive [VAr] power } \\ \sigma & \text { Leakage factor }=1-L_{m}^{2} /\left(L_{p} L_{s}\right) \\ & \end{array}$

\section{INTRODUCTION}

A conventional DFIG [1] has been a widely adopted option of many large-scale wind turbine manufacturers [2], [3] by virtue of its good overall performance, low-cost fractional power electronics, and absence of expensive rare earth permanent magnets with market supply chain volatilities [4]. In WECS, the operating speed ranges are relatively narrow (e.g. about 2:1 or so) allowing one to utterly exploit the DFIG slippower recovery property through cost savings of the typically $70 \%$ derated bi-directional power converter [1]. The latter has also been reported to feature lower failure rates than its fullsize counterpart used for synchronous generator based WECS [5]. However, these capital and running cost benefits may be offset by the DFIG main drawbacks, the compromised reliability and regular servicing of brush gear, as well as hardware protection complexities to satisfy the grid integration codes in making the small inverter LVRT compliant [1], [6].

The above DFIG limitations can be mostly eliminated with the BDFG technologies, while retaining all of the claimed advantages [6]-[8]. The BDFG can not only offer further cost cuts by the high reliability and maintenance-free operation of brushless construction [3], but the superior LVRT characteristics without a crowbar too due to the proportionally larger impedances, and hence reduced fault currents, than the equivalent DFIG [6], [9], [10]. Apart from the target WECS, stand-alone wind [11] and/or ship shaft power generation applications [12] are feasible.

The BDFG has a standard dual 3-phase winding stator structure with the primary (power) winding being directly connected to the utility grid, and the secondary (control) winding being usually fed via a double 'back-to-back' partially-rated bridge, as in the DFIG case. There are two quite distinct BDFG types, the one with a reluctance rotor, known as the BDFRG (Fig. 1) [13], and the other with a 'nested' cage rotor, called the BDFIG [14]. In order to achieve magnetic interaction between the two stator windings of different pole numbers and applied frequencies, the rotor poles must total the stator pole-pairs [13], [14]. This means that with the same number of rotor poles and winding frequencies, the BDFG would turn at around half the DFIG speed rendering it naturally a medium-speed machine and avoiding the need for the troublesome high-speed stage of the 3-stage gearbox in WECS [3]. A modern reluctance rotor can provide the higher efficiency prospects [15], less parameter dependent dynamic modeling [14], [16], and intrinsically decoupled control of torque and reactive power [17]-[19] unlike the BDFIG [20], [21]. The BDFRG control is thus the subject of this paper. 


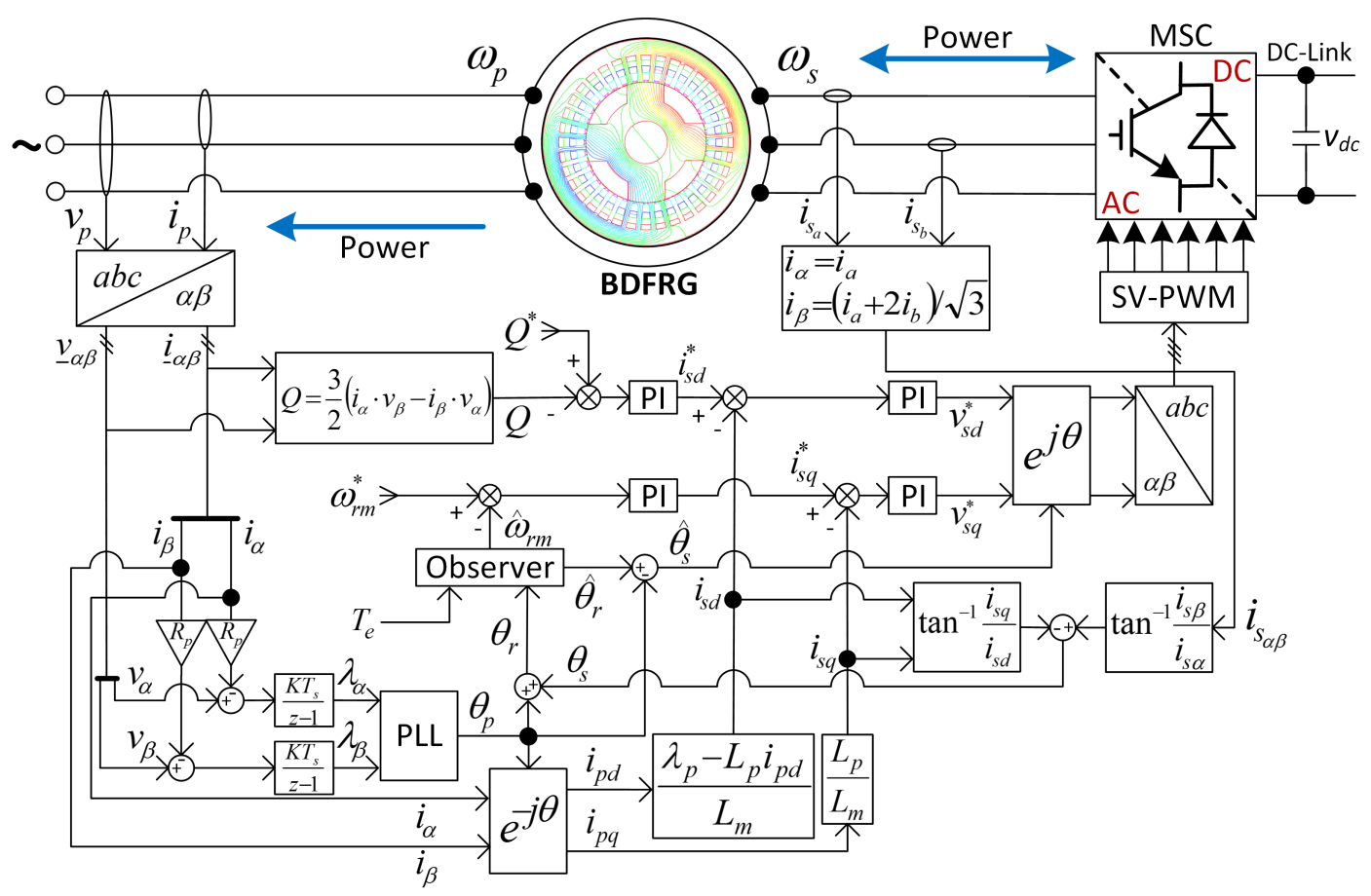

Fig. 1. A block-scheme of the sensorless speed FOC configuration for the space-vector-PWM inverter-fed BDFRG.

A VOC approach for the BDFRG was proposed and experimentally verified, albeit for the unloaded machine, in [17]. The follow-up theoretical preliminaries on this concept have not been practically validated [18], [19]. The same applies to the sliding mode control theory in [22]. On the other hand, DTC has been implemented in sensor [23] and sensor-less speed modes [19] but supported with unsatisfactory no-load test results as in [17]. A much improved response has been obtained by minimising the machine parameter dependence and sensitivity issues of this scheme in the alternative DTC, where the measurable primary reactive power is controlled instead of the estimated secondary flux [24], [25]. A complete parameterfreedom has been further achieved in its DPC concurrent [26]. However, the experiments discussed in [24]-[26] were done at fixed BDFRG loads of little interest to real WECS. Although they can be credited with ease of stator frame implementation without rotor position or velocity inputs, the hysteresis DT(P)C algorithms in [24]-[26] are all executed at variable switching rates and exhibit a generally worse harmonic content than the VOC, and especially its FOC correlative.

Significant contributions to the early VOC research [17] have been recently made with the comparative development and comprehensive practical studies of the two robust VOC and FOC techniques for the adjustable speed BDFRM (e.g. motoring) [27], [28] and the BDFRG [29], [30] under both constant [29] and variable loading conditions [27], [28], [30]. Similar realistic computer simulations of WECS using a $2 \mathrm{MW}$ BDFRG design from [7] have been documented in [8].

The majority of the existing methods for the BDFRG(M) require a shaft position sensor for current and/or speed control as well as to provide the drive train velocity information for the MPPT in WECS [1]. Sensorless operation would bring an extra degree of reliability and operation \& maintenance cost reductions [5]. However, these conveniences often come with some performance trade-offs by introducing the inevitable machine model reliance necessary for the position or speed estimation as demonstrated in the DTC case [19]. An exception is the latest development of a viable speed sensorless FOC scheme in [31], which has been shown to possess good disturbance rejection capabilities and smooth response using the maximum torque per inverter ampere strategy [18]. This paper is an extension to the work in [31] by presenting the principles and experimental results of reactive power control implementation on a custom-built BDFRG for speed dependent WECS-alike loading profiles.

\section{BDFRG OPERATING PRINCIPLES}

The electro-mechanical energy conversion in the machine takes places under the following angular velocity and pole conditions with the mechanical power relationships reflecting the participation of each winding [16], [18]:

$$
\begin{aligned}
\omega_{r m} & =\frac{\omega_{p}+\omega_{s}}{p_{p}+p_{s}}=\left(1+\frac{\omega_{s}}{\omega_{p}}\right) \cdot \frac{\omega_{p}}{p_{r}}=\left(1+\frac{\omega_{s}}{\omega_{p}}\right) \cdot \omega_{s y n} \\
P_{m} & =T_{e} \cdot \omega_{r m}=\frac{T_{e} \cdot \omega_{p}}{p_{r}}+\frac{T_{e} \cdot \omega_{s}}{p_{r}}=P_{p}+P_{s}
\end{aligned}
$$

where $\omega_{s}>0$ if $\omega_{r m}>\omega_{s y n}$, else ${ }^{1} \omega_{s}<0$ and $\omega_{r m}<\omega_{s y n}$. Whereas, $\omega_{s}=0$ (i.e. DC secondary) refers to the synchronous

\footnotetext{
${ }^{1}$ The 'negative' frequency at sub-synchronous speeds means the opposite phase sequence of the secondary to the primary winding i.e. 'clockwise' rotation of the respective vectors in the $d_{s}-q_{s}$ frame as indicated in Fig. 2.
} 
speed operation $\left(\omega_{r m}=\omega_{s y n}\right)$ as with a classical $2 p_{r}$-pole wound field turbo-machine.

It could be easily shown using (1) that if a variable speed range of 2:1 is required in WECS, the corresponding frequency ratio should be $\omega_{p} / \omega_{s}=3$, which implies the inverter real power rating of circa $P_{s} \approx 0.21 P_{m}$ according to (2).

\section{FOC MOdELling Aspects}

The space-vector equations for the primary and secondary windings in rotating reference frames (Fig. 2) using standard notation and motoring (BDFRM) convention are [16]:

$$
\left.\begin{array}{c}
\underline{v}_{p}=R_{p} \underline{i}_{p}+\frac{d \underline{\lambda}_{p}}{d t}=R_{p} \underline{i}_{p}+j \omega_{p} \cdot \underbrace{\left(L_{p} \underline{i}_{p}+L_{m} \underline{i}_{s m}^{*}\right)}_{\underline{\lambda}_{p}} \\
\underline{v}_{s}=R_{s} \underline{i}_{s}+\frac{d \underline{\lambda}_{s}}{d t}=R_{s} \underline{i}_{s}+j \omega_{s} \cdot \underbrace{\left(L_{s} \underline{i}_{s}+L_{m} \underline{i}_{p m}^{*}\right)}_{\underline{\lambda}_{s}}
\end{array}\right\}
$$

where $\underline{i}_{p m}$ and $\underline{i}_{s m}$ are the magnetically coupled (magnetizing) current vectors of the actual primary $\left(\underline{i}_{p}\right)$ and secondary $\left(\underline{i}_{s}\right)$ current counterparts rotating at different velocities (Fig. 2). This peculiar frequency modulating action of the rotor manifests itself through the following important vector equalities for the sensorless controller design: $\underline{i}_{p m}=\underline{i}_{p}=i_{p} e^{j \varepsilon}$ and $\underline{i}_{s m}=\underline{i}_{s}=i_{s} e^{j \gamma}$ in the corresponding $d-q$ frames as illustrated in Fig. 2 [16]. Given (1), such frame choice facilitates control as the secondary $d q$ currents are then DC.

The flux FOC forms of (3), and the respective torque and 3 -phase reactive power expressions, now become [27]-[31]:

$$
\begin{aligned}
& \underline{\lambda}_{p}=\underbrace{L_{p} i_{p d}+L_{m} i_{s m_{d}}}_{\lambda_{p d}=\lambda_{p}}+j \cdot \underbrace{\left(L_{p} i_{p q}-L_{m} i_{s m_{q}}\right)}_{\lambda_{s d}} \\
& \underline{\lambda}_{s}=\underbrace{\sigma L_{s} i_{s d}+\lambda_{m d}}_{\lambda_{s q}=0}+j \cdot \underbrace{\underline{\lambda}_{\underline{\lambda}_{m}}}_{\lambda_{s}\left(\sigma L_{s} i_{s q}+\lambda_{m q}\right)} \\
&=\sigma L_{s} \underline{i}_{s}+\underbrace{\frac{L_{m}}{L_{p}} \underline{\lambda}_{p}^{*}}_{\lambda_{m}}=\sigma L_{s} \underline{i}_{s}+\frac{L_{m}}{L_{p}} \lambda_{p} \\
& Q=\frac{P_{p} p_{r}}{\omega_{p}}=\frac{3 p_{r}}{2} \lambda_{p} i_{p q}=\frac{3 p_{r} L_{m}}{2 L_{p}} \lambda_{p} i_{s q}=\frac{3 p_{r}}{2} \lambda_{m} i_{s q} \\
& T_{p} \lambda_{p} i_{p d}=\frac{3}{2} \frac{\omega_{p} \lambda_{p}}{L_{p}}\left(\lambda_{p}-L_{m} i_{s d}\right)
\end{aligned}
$$

Note that, with the grid-locked primary winding and approximately constant $\lambda_{p}$, and thus $\lambda_{m}$, the FOC frame-flux vector alignment in Fig. 2 leads to inherently decoupled control of $T_{e}$ and $Q$ through $i_{s q}$ and $i_{s d}$ by removing the problematic VOC cross-coupling terms from (7) and (8). If left uncompensated, the latter can severely deteriorate the VOC response quality, particularly with smaller machines, as experimentally verified in [27]-[30]. The FOC approach is therefore more generic and applicable to a range of machine sizes from this point of view. Furthermore, it is amenable to sensorless control as shown in the sequel. Another important control implication of $T_{e} \sim i_{s q}$ and $Q \sim i_{s d}$ is that $i_{s q}$ and $i_{s d}$ can serve as the reference outputs of the speed and $Q$ loops avoiding the use of (7) and (8) and handling the associated parameter uncertainties

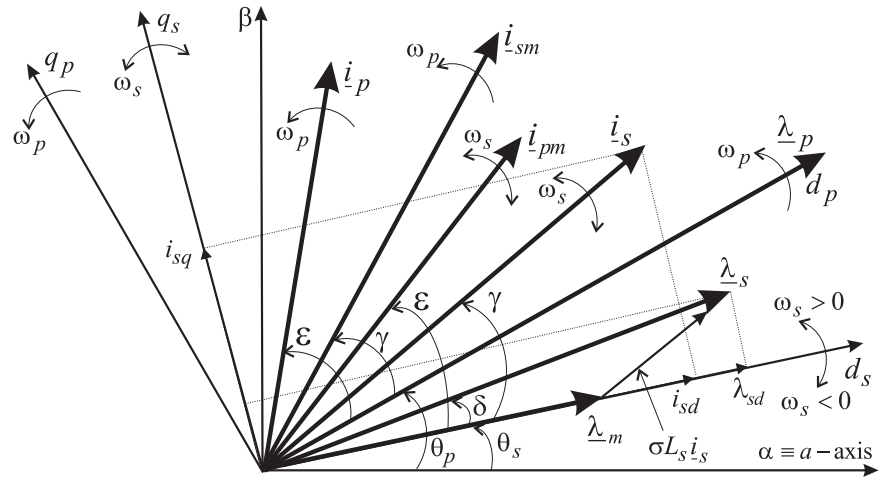

Fig. 2. A FOC phasor diagram with the key vectors and reference frames.

through PI tuning (Fig. 1). The controller robustness of the original implementation in [31] can be elevated in this way.

\section{Sensorless FOC Design}

The $\underline{\lambda}_{p}=\lambda_{p} e^{j \theta_{p}}$ stationary frame components (Fig. 2) for the Y-connected primary winding with an isolated neutral point and 'ABC' phase sequence are calculated from the line voltage and current measurements using (3) as follows:

$$
\left.\begin{array}{l}
\lambda_{\alpha}=\int\left(v_{\alpha}-R_{p} i_{\alpha}\right) d t=\int\left(\frac{v_{A B}+v_{A C}}{3}-R_{p} i_{A}\right) d t \\
\lambda_{\beta}=\int\left(v_{\beta}-R_{p} i_{\beta}\right) d t=\int\left(\frac{v_{B C}}{\sqrt{3}}-R_{p} \frac{i_{A}+2 i_{B}}{\sqrt{3}}\right) d t
\end{array}\right\}
$$

The generated $\lambda_{\alpha \beta}$ estimates are input to a conventional PLL to filter out the transducer DC offset effects and noisy measurements in order to get the most accurate $\theta_{p}$ as the FOC foundation. This angle is then used to find the $d_{p}-q_{p}$ currents, $i_{p d}$ and $i_{p q}$, and the rotor angle $\left(\theta_{r}\right)$ from the angular position version of (1) i.e. $\theta_{r}=p_{r} \theta_{r m}=\theta_{p}+\theta_{s}$, as shown in Fig. 1.

The $d_{s}$-axis position $\left(\theta_{s}\right)$ above is identified using (4) and the fact that $\underline{i}_{s m}=\underline{i}_{s}$ (Fig. 2):

$$
\left.\begin{array}{c}
L_{p} i_{p d}+L_{m} i_{s m_{d}}=\lambda_{p} \Longrightarrow i_{s d}=i_{s m_{d}}=\frac{\lambda_{p}-L_{p} i_{p d}}{L_{m}} \\
L_{p} i_{p q}-L_{m} i_{s m_{q}}=0 \Longrightarrow i_{s q}=i_{s m_{q}}=\frac{L_{p}}{L_{m}} i_{p q}
\end{array}\right\}
$$

Notice that the feedback currents in Fig. 1 are directly determined by (10) regardless of $\theta_{s}$ or $\theta_{r}$ errors. In addition, $\theta_{s}$ can now be obtained from the measured secondary currents by applying the obvious angular relationships from Fig. 2:

$$
\begin{aligned}
\theta_{s} & =\tan ^{-1} \frac{i_{s \beta}}{i_{s \alpha}}-\tan ^{-1} \frac{i_{s q}}{i_{s d}} \\
& =\tan ^{-1} \frac{i_{a}+2 i_{b}}{\sqrt{3} i_{a}}-\tan ^{-1} \frac{L_{p} i_{p q}}{\lambda_{p}-L_{p} i_{p d}}
\end{aligned}
$$

Therefore, apart from $R_{p}$ (through $\lambda_{p}$ ) with smaller machines, the use of (12) only needs the $L_{p}$ knowledge. Yet, as $\theta_{s}$ can still be affected by measurement noise, the raw $\theta_{r}=\theta_{p}+\theta_{s}$ values are passed through a common load-model based PI observer [31], [32] to eradicate erroneous estimates for accurate $\hat{\omega}_{r m}$ predictions. The filtered $\hat{\theta}_{r}$ is fed back to further enhance the quality of $\hat{\theta}_{s}$ estimation, the emanating PWM signals, and in turn the controller response. 


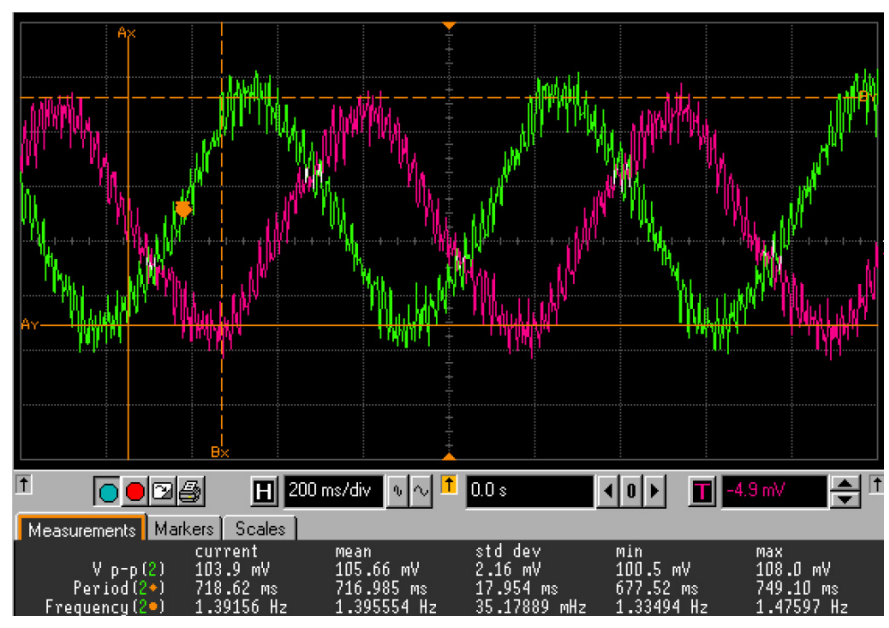

Fig. 3. Oscillograms of the steady-state currents in two phases of the shorted secondary winding for the unloaded BDFRG at $\approx 730 \mathrm{rev} / \mathrm{min}$.

TABLE I

THE BDFRG PARAMETERS AND RATINGS

\begin{tabular}{||l||l||}
\hline \hline Rotor inertia $[J]$ & $0.2 \mathrm{kgm}^{2}$ \\
\hline Primary resistance $\left[R_{p}\right]$ & $11.1 \Omega$ \\
\hline Secondary resistance $\left[R_{s}\right]$ & $13.5 \Omega$ \\
\hline Primary inductance $\left[L_{p}\right]$ & $0.41 \mathrm{H}$ \\
\hline Secondary inductance $\left[L_{s}\right]$ & $0.57 \mathrm{H}$ \\
\hline Mutual inductance $\left[L_{m}\right]$ & $0.34 \mathrm{H}$ \\
\hline Rotor poles $\left[p_{r}\right]$ & 4 \\
\hline \hline Primary power $\left[P_{r}\right]$ & $1.6 \mathrm{~kW}$ \\
\hline Rated speed $\left[n_{r}\right]$ & $950 \mathrm{rev} / \mathrm{min}$ \\
\hline Stator currents $\left[I_{p, s}\right]$ & $2.5 \mathrm{~A} \mathrm{rms}$ \\
\hline Stator voltage $\left[V_{p}\right]$ & $400 \mathrm{~V} \mathrm{rms}$ \\
\hline Stator frequency $\left[f_{p}\right]$ & $50 \mathrm{~Hz}$ \\
\hline Winding connections & $\mathrm{Y} / \mathrm{Y}$ \\
\hline Stator poles $[p / q]$ & $6 / 2$ \\
\hline \hline
\end{tabular}

\section{LABORATORY TESTS}

The BDFRG was started as a slip ring induction machine up to the steady no-load speed (Fig. 3), and the inverter was then enabled on the fly. The experimental results were generated by running the sensorless algorithm in Fig. 1 on a dSPACE ${ }^{\circledR}$ DS1 103 platform at $2.5 \mathrm{kHz}$. The specifications of the BDFRG prototype are summarised in Table I. These data have been used to create the following shaft torque-speed profile to emulate the MPPT characteristic of WECS in the base speed region [1]:

$$
T_{L}=-\frac{P_{r}}{\omega_{r}} \cdot\left(\frac{n_{r m}}{n_{r}}\right)^{2} \approx-16 \cdot\left(\frac{n_{r m}}{950}\right)^{2} \mathrm{Nm}
$$

This expression is implemented using a commercial Parker ${ }^{\circledR}$ DC drive operated in torque mode. The other relevant details about the BDFRG test facility can be found in [24]-[31].

The results in Fig. 4 demonstrate an excellent tracking of the ramp speed reference trajectory in a limited range of [550950] rev/min around the synchronous speed (750 rev/min). The effectiveness of the machine sensorless operation is clearly verified in either synchronous, super-synchronous or subsynchronous speed modes and with marginal speed estimation errors under both steady-state and transient conditions. The captured $Q$ waveform properly follows the desired set-point showing overall immunity to the $P$ variations and providing convincing evidence of the robustness afforded by the inherently decoupled FOC nature as expected from (7) and (8).

The observer low-pass filtering abilities are more than evident from the speed error plot in Fig. 4, which represents the deviations of the observer estimates $\left(\hat{\omega}_{r m}\right)$ from the actual encoder measurements $\left(\omega_{r m}\right)$. Although the raw $\theta_{r}$ can be notably noisy, much the same as recorded in [31] but not in this paper for space reasons, a considerable improvement in accuracy is achieved by processing $\theta_{r}$ considering the virtually overlapping trend of the corresponding $\hat{\omega}_{r m}$ and $\omega_{r m}$ traces over the entire speed range. Such an impressive sensorless controller response essentially comes from to the bulk of the quality estimates produced by the closed-loop configuration of both the position estimator itself and the high-performance observer as its central part.

The measured secondary current waveforms in Fig. 5 illustrate the phase sequence reversal while the BDFRG is riding through the synchronous speed from $950 \mathrm{rev} / \mathrm{min}$ to $550 \mathrm{rev} / \mathrm{min}$. At super-synchronous speeds, the $d_{s}-q_{s}$ frame, and the accompanying secondary vectors including $\underline{i}_{s}$, rotate in a positive (anti-clockwise) direction indicated by $\omega_{s}>0$ in (1). In sub-synchronous speed mode, however, the secondary phase sequence is opposite to the primary with $\underline{i}_{s}$ now rotating clock-wise when $\omega_{s}<0$ in (1). Notice that $\underline{i}_{s}$ becomes stationary at synchronous speed (750 rev/min) as the secondary currents are then DC i.e. $\omega_{s}=0$ in (1).

Finally, Fig. 6 is presented to reinforce the absence of crosscoupling not only in the $Q$ response to ramp variations in $P$, but also the other way around in case of a sudden step change in $Q$ reference, for the machine operating at $1000 \mathrm{rev} / \mathrm{min}$. Both the $P$ and $Q$ responses are visibly smooth and show no apparent signs of distortion pointing out again the excellent disturbance rejection properties of the controller.

\section{CONCLUSIONS}

A field-oriented speed and reactive power control algorithm for sensorless operation of the BDFRG has been validated by tests on a small machine prototype under wind turbine-alike loading conditions emulated in a laboratory environment. The scheme under consideration has been previously proposed by the author(s) in their latest work where the reactive power control has not been demonstrated. This gap has been filled by the experimental results presented in this paper.

The control system design is structured around the rotor position and speed estimation technique with a standard Luenberger-type load model based observer playing a pivotal role. This approach has allowed the controller to effectively substitute the encoder measurements by providing high-quality estimates of the angular position and velocity. A smooth and robust response has been consequently achieved in a narrow speed range where the variable secondary frequencies are low and down to zero at synchronous speed. Such good performance can be attributed to the rotor position independent 

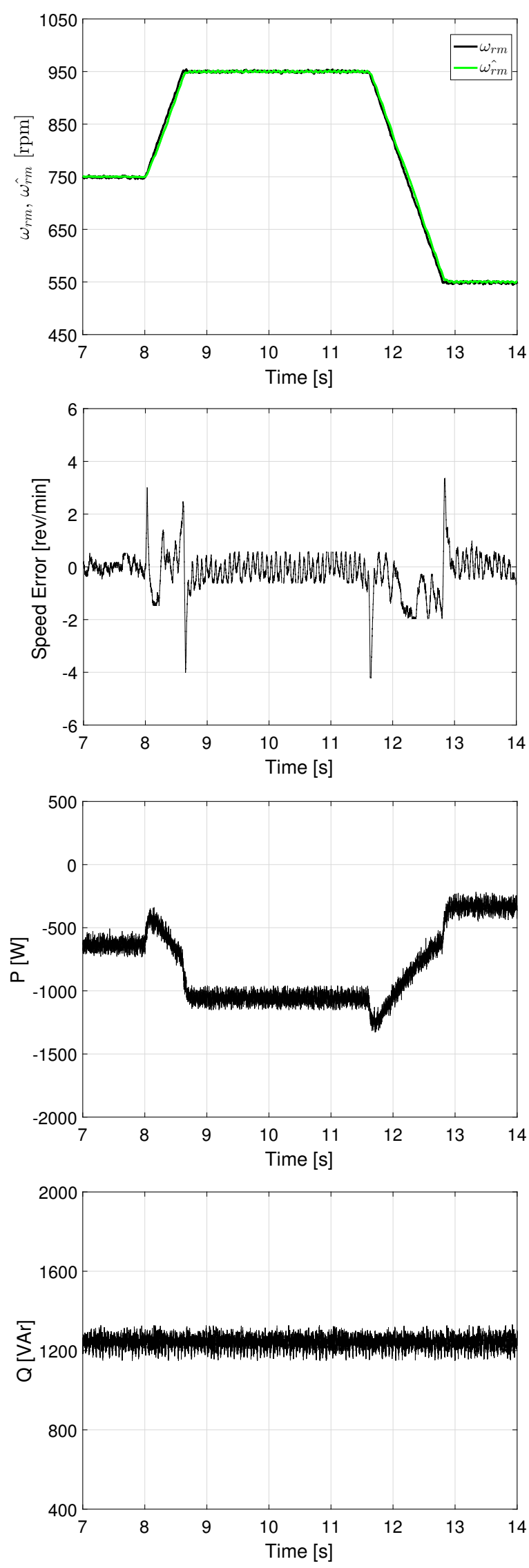

Fig. 4. Experimental verification of the BDFRG sensorless speed control.

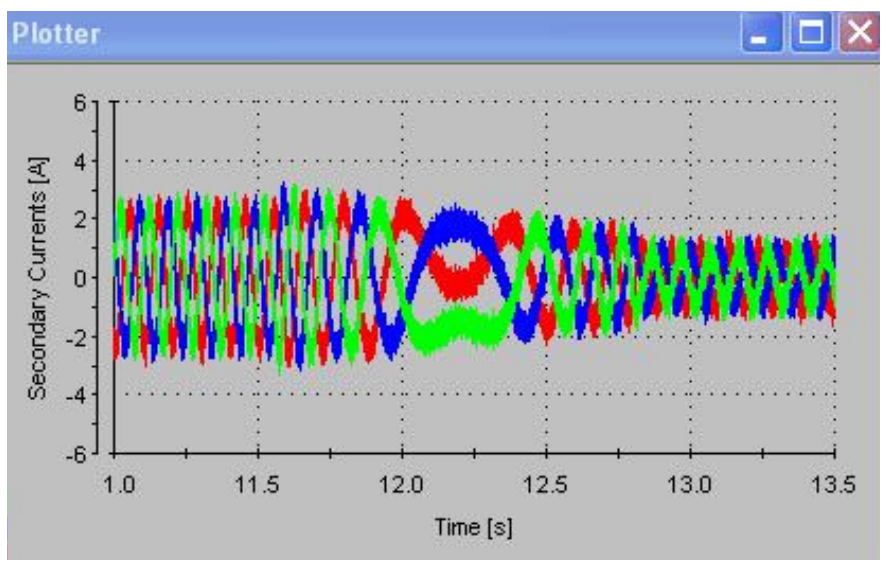

Fig. 5. The secondary currents showing a phase sequence reversal from super to sub-synchronous speed mode as captured on the $\mathrm{dSPACE}^{\circledR}$ desktop.

current control feedback coupled with the relatively light reliance on the machine parameters of the entire estimation procedure.

\section{REFERENCES}

[1] R. Cardenas, R. Pena, S. Alepuz, and G. Asher, "Overview of control systems for the operation of DFIGs in wind energy applications," IEEE Transactions on Industrial Electronics, vol. 60, no. 7, pp. 2776-2798, 2013.

[2] M. Liserre, R. Cardenas, M. Molinas, and J. Rodriguez, "Overview of multi-MW wind turbines and wind parks," IEEE Transactions on Industrial Electronics, vol. 58, no. 4, pp. 1081-1095, Apr. 2011.

[3] H. Polinder, J. Ferreira, B. Jensen, A. Abrahamsen, K. Atallah, and R. McMahon, "Trends in wind turbine generator systems," IEEE Journal of Emerging and Selected Topics in Power Electronics, vol. 1, no. 3, pp. 174-185, Sept 2013.

[4] J. G. Njiri and D. Soffker, "State-of-the-art in wind turbine control: Trends and challenges," Renewable and Sustainable Energy Reviews, vol. 60, pp. 377-393, 2016.

[5] J. Carroll, A. McDonald, and D. McMillan, "Reliability comparison of wind turbines with DFIG and PMG drive trains," IEEE Transactions on Energy Conversion, vol. 30, no. 2, pp. 663-670, June 2015.

[6] S. Tohidi, P. Tavner, R. McMahon, H. Oraee, M. Zolghadri, S. Shao, and E. Abdi, "Low voltage ride-through of DFIG and brushless DFIG: Similarities and differences," Electric Power Systems Research, vol. 110, pp. 64-72, May 2014.

[7] D. G. Dorrell and M. Jovanović, "On the possibilities of using a brushless doubly-fed reluctance generator in a 2 MW wind turbine," IEEE Industry Applications Society Annual Meeting, pp. 1-8, Oct. 2008.

[8] S. Ademi and M. Jovanovic, "Control of emerging brushless doublyfed reluctance wind turbine generators," in Large Scale Renewable Power Generation, ser. Green Energy and Technology, J. Hossain and A. Mahmud, Eds. Springer Singapore, 2014, pp. 395-411.

[9] S. Tohidi, H. Oraee, M.-R. Zolghadri, S. Shao, and P. Tavner, "Analysis and enhancement of low-voltage ride-through capability of brushless doubly fed induction generator," IEEE Transactions on Industrial Electronics, vol. 60, no. 3, pp. 1146-1155, March 2013.

[10] T. Long, S. Shao, P. Malliband, E. Abdi, and R. McMahon, "Crowbarless fault ride-through of the brushless doubly fed induction generator in a wind turbine under symmetrical voltage dips," IEEE Transactions on Industrial Electronics, vol. 60, no. 7, pp. 2833-2841, 2013.

[11] F. Zhang, L. Zhu, S. Jin, W. Cao, D. Wang, and J. L. Kirtley, "Developing a new SVPWM control strategy for open-winding brushless doubly fed reluctance generators," IEEE Transactions on Industry Applications, vol. 51, no. 6, pp. 4567-4574, Nov/Dec 2015.

[12] Y. Liu, W. Ai, B. Chen, K. Chen, and G. Luo, "Control design and experimental verification of the brushless doubly-fed machine for standalone power generation applications," IET Electric Power Applications, vol. 10 , no. 1 , pp. $25-35,2016$. 

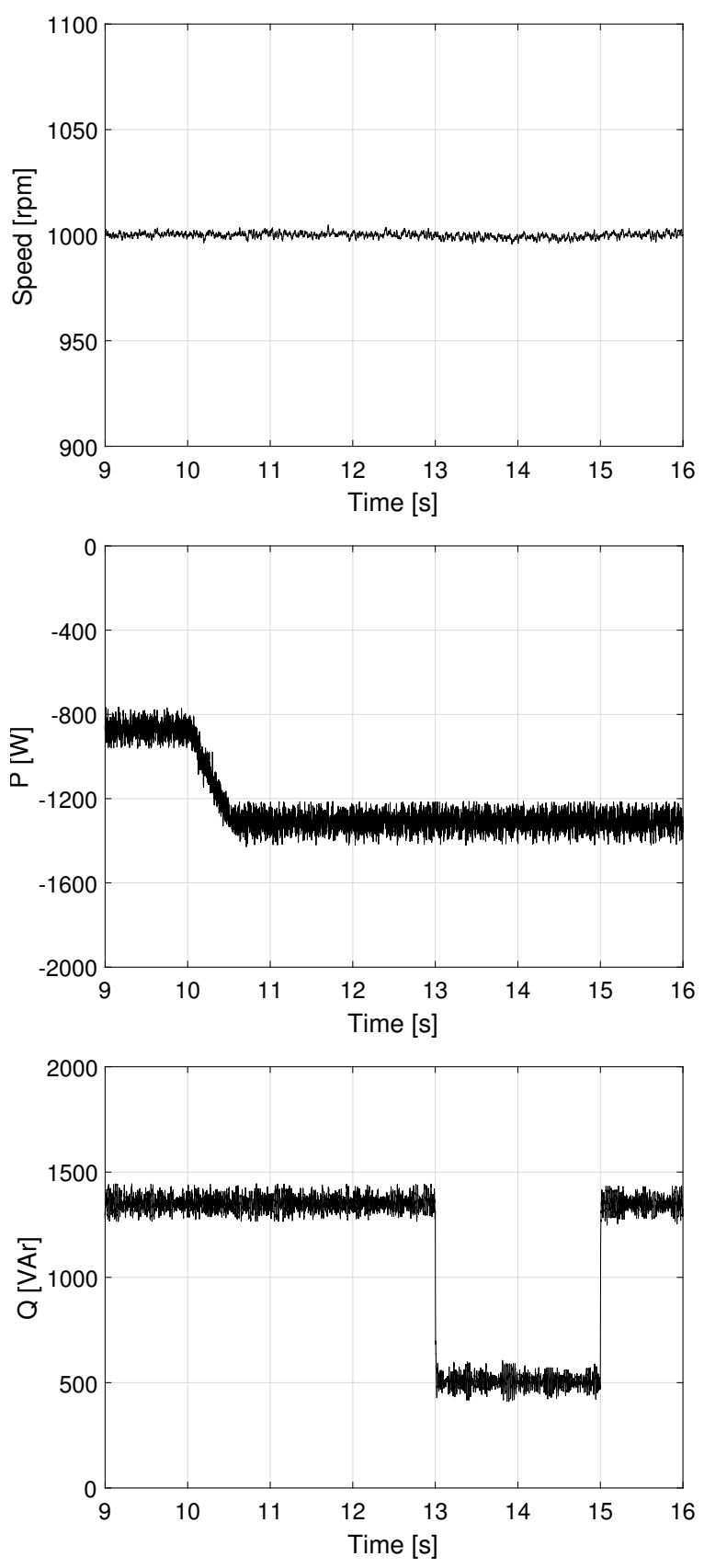

Fig. 6. Super-synchronous sensorless operation demonstrating excellent disturbance rejection abilities and smooth response of the decoupled FOC to $P$ and/or $Q$ variations at $1000 \mathrm{rpm}$.

[13] A. Knight, R. Betz, and D. Dorrell, "Design and analysis of brushless doubly fed reluctance machines," IEEE Transactions on Industry Applications, vol. 49, no. 1, pp. 50-58, Jan/Feb 2013.

[14] A. Oraee, E. Abdi, S. Abdi, R. McMahon, and P. Tavner, "Effects of rotor winding structure on the BDFM equivalent circuit parameters," IEEE Transactions on Energy Conversion, vol. 30, no. 4, pp. 16601669, Dec 2015.

[15] F. Wang, F. Zhang, and L. Xu, "Parameter and performance comparison of doubly-fed brushless machine with cage and reluctance rotors," IEEE Transactions on Industry Applications, vol. 38, no. 5, pp. 1237-1243, 2002.

[16] R. E. Betz and M. G. Jovanović, "Introduction to the space vector modelling of the brushless doubly-fed reluctance machine," Electric
Power Components and Systems, vol. 31, no. 8, pp. 729-755, 2003.

[17] L. Xu, L. Zhen, and E. Kim, "Field-orientation control of a doubly excited brushless reluctance machine," IEEE Transactions on Industry Applications, vol. 34, no. 1, pp. 148-155, Jan/Feb 1998.

[18] M. G. Jovanovic, R. E. Betz, and J. Yu, "The use of doubly fed reluctance machines for large pumps and wind turbines," IEEE Transactions on Industry Applications, vol. 38, pp. 1508-1516, 2002.

[19] M. Jovanović, "Sensored and sensorless speed control methods for brushless doubly fed reluctance motors," IET Electric Power Applications, vol. 3, no. 6, pp. 503-513, 2009.

[20] F. Barati, R. McMahon, S. Shao, E. Abdi, and H. Oraee, "Generalized vector control for brushless doubly fed machines with nested-loop rotor," IEEE Transactions on Industrial Electronics, vol. 60, no. 6, pp. 24772485, June 2013.

[21] R. Zhao, A. Zhang, Y. Ma, X. Wang, J. Yan, and Z. Ma, "The dynamic control of reactive power for the brushless doubly fed induction machine with indirect stator-quantities control scheme," IEEE Transactions on Power Electronics, vol. 30, no. 9, pp. 5046-5057, Sept 2015.

[22] F. Valenciaga, "Second order sliding power control for a variable speedconstant frequency energy conversion system," Energy Conversion and Management, vol. 52, no. 12, pp. 3000-3008, 2010.

[23] M. G. Jovanović, J. Yu, and E. Levi, "Encoderless direct torque controller for limited speed range applications of brushless doubly fed reluctance motors," IEEE Transactions on Industry Applications, vol. 42, no. 3, pp. 712-722, 2006.

[24] H. Chaal and M. Jovanović, "Practical implementation of sensorless torque and reactive power control of doubly fed machines," IEEE Transactions on Industrial Electronics, vol. 59, no. 6, pp. 2645-2653, 2012.

[25] H. Chaal and M. Jovanovic, "Toward a generic torque and reactive power controller for doubly fed machines," IEEE Transactions on Power Electronics, vol. 27, no. 1, pp. 113-121, 2012.

[26] - "Power control of brushless doubly-fed reluctance drive and generator systems," Renewable Energy, vol. 37, no. 1, pp. 419-425, Jan 2012

[27] S. Ademi and M. Jovanović, "High-efficiency control of brushless doubly-fed machines for wind turbines and pump drives," Energy Conversion and Management, vol. 81, pp. 120-132, May 2014.

[28] S. Ademi, M. Jovanović, and M. Hasan, "Control of brushless doublyfed reluctance generators for wind energy conversion systems," IEEE Transactions on Energy Conversion, vol. 30, no. 2, pp. 596-604, June 2015.

[29] S. Ademi and M. Jovanović, "Vector control methods for brushless doubly fed reluctance machines," IEEE Transactions on Industrial Electronics, vol. 62, no. 1, pp. 96-104, Jan 2015.

[30] S. Ademi and M. Jovanovic, "Control of doubly-fed reluctance generators for wind power applications," Renewable Energy, vol. 85, pp. 171-180, January 2016.

[31] S. Ademi, M. G. Jovanović, H. Chaal, and W. Cao, "A new sensorless speed control scheme for doubly fed reluctance generators," IEEE Transactions on Energy Conversion, vol. PP, no. 99, pp. 1-9, 2016.

[32] R. Lorenz and K. Patten, "High-resolution velocity estimation for alldigital, ac servo drives," IEEE Transactions on Industry Applications, vol. 27, no. 4, pp. 701-705, July/August 1991. 